\title{
Historical exploration of the Korean special school physical education and the disability sports environment
}

\author{
Duck-Hyun, Nam* \\ Korea National University of Education
}

\begin{abstract}
[Purpose] This study examines the Physical Education curriculum history of special schools, and then in-depth grasps the process of how the sports environment for the disabled has changed by age. [Method] The research method was literature review analyzing papers, reports and newspapers. For the concrete process, this study verified the relationship between the research subject and the collected data through experts and historians with disabilities to verify the sports data for the disabled. [Results] First, the process of physical education management of special schools is as follows. in the 1940's and 50 's special schools, physical education was carried out simply by gymnastics. but, special schools were differentiated by the characteristics of the disabled, and the institutional foundation for physical education was also imitated by the 1960s, 1970s and 1980s, special schools were shortened in physical education time due to the increase in the number of courses and the strengthening of disability coping programs. in the 1990s, as special sports curriculum was established, customized prescription for students with disabilities was implemented. Second, the process of changing disability sports is as follows. In the 1960s and 1970s, disability sports were mainly focused on special schools, while in the 1980s, disability sports were expanded by the government. in particular, the hosting of the 88 Seoul Olympics and Seoul Paralympics provides an opportunity to equip the disabled with a system, organization and facilities. in the 1990s disability sports was meaningful in terms of academic progress, and with the quantitative growth of the 1980s and the academic foundations of the 1990s, disability sports in the 2000s provided a legal basis and improved welfare conditions for the disabled. In the future, it is necessary to find a way to solve the value of physical education for the disabled more reasonably.
\end{abstract}

Key words: Special School, Physical Education, Curriculum, Disability Sports, Seoul Olympics and Seoul Paralympics

\section{서 론 \\ 문명의 발전은 그 빛만큼 그늘도 나타나게 한다. 이른 바 자본주의 체제에선 효익만을 강조했으며 장애인은 이}

논문 투고일 : 2020. 03. 02.

논문 수정일 : 2020. 05. 07.

게재 확정일 : 2020. 06. 05.

* 교신저자 : 남덕현(nam8dan@ hanmail.net).
러한 풍조에 자연 소외될 수밖에 없었다. 한국도 예외는 아니어서 이른바 급속한 산업 발전 환경이 노동 현장을 장악하면서 표준화되고 기계화된 노동에 적응하지 못한 장애인들은 무능력자로 낙인찍히며 노동 현장으로부터 밀려나고 사회체제에서까지 근본적으로 배제당하기 시 작했다.

하지만 현재는 다르게 변화하고 있다. 다변화 시대를 맞이하여 사회적 약자를 위한 복지와 권익증진이 시대적 
대세로 주목받고 있으며 장애인은 일반인과 동등한 삶의 질을 누릴 기회를 얻고 있다. 더불어 질 좋은 장애인 삶을 위한 체육을 통한 신체 및 정신 건강 차원의 관심도 고조 되어 장애인체육 진흥을 위한 사회 분위기가 점차 확대되 어 가고 있다.

장애인체육이 우리에게서 관심을 끌게 된 시기는 1980 년대에 들어서이다. 그 이유는 1988년 서울올림픽에 뒤이 어 패럴림픽 개최는 필수 권장 사항이었기 때문이었다. 이 에 따라 정부는 1981 년에 제1회 전국장애인체육대회를 개최하여 패럴림픽에 대비하였고 1989 년부터 장애인체 육 행정을 담당하는 한국장애인복지체육회가 결성되면서 운영 기반을 마련한다. 이후 2005년 국민체육진흥법 제정 이후 정부 진흥정책에 따라 장애인체육은 보건 및 재활의 개념을 넘어서 체육복지 정책이 추진되어 보다 구체적 성 과가 나타나고 있다(Ministry of Culture, Sports and Tourism, 2018).

위에서 살펴볼 수 있듯이 장애인체육은 개인의 건강관 리뿐만 아니라 사회참여와 욕구충족, 복지수준 향상 차원 에서 일반인과 더불어 체육정책의 중요한 영역으로 부각 되고 있다. 장애인에게 있어 신체활동을 통해 얻어지는 체육의 가치는 비장애인들에게 뿐만 아니라 장애인 생활 체육 참가자들에게 장애를 극복하고 사회인으로 통합한 다는 측면에서 중요한 의미를 지닌다(Choi, 2016). 따라 서 시대별 장애인체육의 변화과정을 살펴 향후의 미래 발 전 방향을 확인하는 것은 퍽 의미 있어 보인다.

장애인체육의 변천과정에 대한 선행연구로는 국내 장 애인체육의 형성과정 역사(Han, 1996), 한.미일 장애인 체육 관련 법률 설치 및 개정과정의 변천 $(R o h ~ \&$ Hwang, 2014), 장애인체육 정책 기조에 따른 행정조직 및 전국장애인체육대회 변천과정 (Lee, 2006), 장애인체 육대회 개최 계획 과정 변화(Choi, 2006), 국민체육진흥 법에 투영된 장애인체육 관련 법률 및 변천과정을 탐색하 고 향후 장애인체육의 법 제도 개선사항을 제시한 연구도 제시되었다(Cho et al., 2012). 이상의 연구는 대회, 제 도 등 세부 분야별 변천 과정을 논하였다. 이후 거시적으 로 장애인체육의 태동과 함께 발전단계를 시기별로 구분 한 장애인체육 연구도 존재한다(Kim \& Je Kal, 2014; Hwang, 2014).

앞서 연구의 문제는 구체적 실증자료를 제시하지 못하
고 있어 장애인체육의 역사를 명확하게 규명하고 있지 못 하는 데 있다. 예를 들면, 1950년대 초를 중심으로 장애 인체육이 형성 발전하였다고 단정하고 있으며 장애인체 육 백서를 기반으로 장애인체육 관련 학회지 및 학위 논 문 내용이 재양산되고 있는 상황이다(Cho \& Gu, 2006; Ministry of Culture \& Tourism, 2007).

이에 본 연구는 선행연구는 물론 문헌에 근거한 실증 적 연구를 기본으로 초기 특수학교를 중심으로 한 장애인 체육 태동과정과 함께 장애인 경기운영 및 조직 변천과정 을 심도 있게 살펴보고자 한다.

장애인체육 시기 구분 선행연구에 의하면 (1) 태동기 (1988 이전), (2) 기반구축기(1988 2004), (3) 도약기 (2005 이후)로 구분한 거시적 시기 구분(Choi, 2018)과 (1) 교육기관의 신체 치료 및 재활 보훈 활동 장애인체육 (1960 이전 1970), (2) 국가 주도 일반 체육 정책과 장 애인체육(1971 1987), (3) 체계화 및 다양한 가치 모색 장애인체육(1988 2004), (4) 전담기관 주도 양적 확산 과 제도 기반 구축 장애인체육(2005 2011), (5) 질적 성 장을 위한 내적 변화의 장애인체육(2012 )과 같은 세부 화된 시기 구분도 있다(Hwang, 2014).

위 시기 구분 논의를 참조해 볼 때 3 시기 구분은 장애 인체육에 대한 세분화된 발전과정을 확인하기엔 제한점 이 있으며 5시기 구분은 특수학교와 장애인체육 전반의 운영체계를 포괄적으로 접근한 경향이 강하다. 이에 본 연구는 특수학교 체육 운영과 연대별 (10년 기준) 장애인 체육 변천과정을 이원화하여 제시하는 것이 장애인체육 의 변화과정을 보다 효과적으로 확인할 수 있다고 보았 다. 이를 위해 다음과 같은 내용을 중심으로 본 연구를 진 행한다.

먼저, 실증적 연구기반을 마련하고자 선행논문, 보고 서는 물론이거니와 초기 신문자료 및 정부 관보(官報)를 중심으로 장애인체육의 연원과 변천과정을 살펴보고자 하였다. 다음으로, 수집된 장애인체육과 관련 자료의 검 증을 위해 장애인체육 전문가 및 역사학자를 통해 연구주 제와 수집 자료의 연관성 여부를 확인하였다. 최종적으로 논문의 완숙성을 위해 반복적 독해 및 숙독으로 유사 주 제 분류 및 문장 정렬로 결과자료의 범주화를 실시하였 다. 


\begin{tabular}{|c|}
\hline 연구자료 선정 \\
\hline 장애인체육 문헌분석(고문헌, 신문자료, 논문, 기관 보고서) \\
\hline$\downarrow$ \\
\hline 자료의 적절성 여부 판단 \\
\hline 전문가 협의로 연구주제와 수집 자료의 연관성 여부 확인 \\
\hline$\downarrow$ \\
\hline 결과자료의 범주화 \\
\hline 반복적 독해 및 숙독으로 유사 주제 분류 및 문장 정렬 \\
\hline
\end{tabular}

Fig. 1. Research Procedure

\section{특수학교의 체육교과과정 검토}

\section{일제강점기 특수학교 체육교과과정 분석}

우리나라에서 장애가 있는 사람들이 근대적 의미의 체 육활동을 시작한 시기는 일제 강점기에 이르러 시작된 제 생원(濟生院)이란 특수학교에서 시작된다. 조선총독부 는 1911년에 제생원을 설립하고(Maeil Sinbo Newspaper, 1911; Joseon Government General, 1911), 그 산하에 한국 최초의 공립 특수교육기관인 제

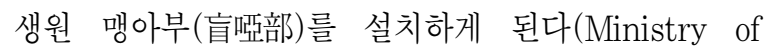
Culture \& Tourism, 2007).

濟生院規程이 公布되다. 내용은 고아, 맹아, 瘋癩者의 교양 구호와 의료를 목적으로 하고 총독 예속하에 京城에 수순을 두며 필요에 따라 각지에 분원 또는 파출소를 두기로 되어 있다(Maeil Sinbo Newspaper, 1911; Joseon Government General, 1911).

구체적으로 보면 초기에는 제생원에 주로 언어장애 및 시각장애(맹아)를 가진 자들을 위한 교육 및 의료를 목적 으로 한 시설이었던 것으로 보이며 실제로 1911년에 조 직 설치 제도를 공표하고 실제로는 1912년에 운영된 것 으로 보인다(Joseon Government General, 1912).

이 세상에 누가 불상하니 누가 불상하니 하야도 압 못보는 사람처럼 불상한 사람은 업슬 것이다. 다가튼 사람으로도 눈 한가지가 업는 까닭에 남과 가티 ⿱⺌兀兀明한 天地를 보지 못하고

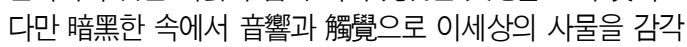

하고 인식하야 生을 보존할 따름이엿다. 沈淸이 가튼 효녀를 저마다 두엇스면 엇덜지 모르지만은 그럿치 안은 이상에는 아모리 천재가 비범한 인물이라도 공부하랴 할수가 업고 따 라서 벌어먹을 길도 업다. 그러함으로 이때까지 그들의 배우 고하는 직업이라는 것은 다만 迷信的의 問卜이나 經을 읽는 것뿐이엿다. 그것도 넉넉한 사람은 자기집에 잇서서 그런 일 을 하지만은 그럿치도 못하고 어려운 사람들은 세발막대를 맛아들보다 더 중히 녁이고 압장을 삼어 몽느으로 도라다니 며 고함을 치고 問卜하기를 애원하다가 엇던 때에는 不良少 年들에게도 『장님XX이 몃쪽이요...』하는 嘲笑까지 바더가며 가련한 일생을 보냇다. 그러나 文明의 ⿱ㅓ⼼澤은 그이들에게도 밋처서 아모리 눈이 업는 그들이라도 보통사람과 다름업시 눈을 뜨고 살게 되엿다. 그것은 다른 것이 안이라 곳 點字法 이다.(紙面에 뚤인 구녕을 손으로 집허 글자 알어내는 법) 이 點字法은 약 100년전에 佛蘭西사람의 푸레유-氏가 綴字 法과 그 기계를 발명하고 그후 30년쯤 뒤에 미국인 뉴요-크 氏가 거의 가튼 기계를 발명하얏스나 뉴요-크氏 ⿹⼯은 미국 한 부분에서만 사용하고 푸레유氏 式은 세계각국에서 가티 사용되여잇다. 현재 조선에서도 이 綴字法을 朝鮮文과 日本 文으로 고처서 온갓 학문을 가르키고 잇다. 이외에 數字-이 것은 어느 나라든지 가튼 綴去 -와 영어, 불어, 독어도 넉넉 히 배흘 수가 잇는 것이다. 盲人에게도 이러한 光明이 잇는 것을 모르고 비관과 한숨으로 지내는 이가 얼마나 만흔가.

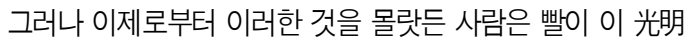
을 차저볼 것이다. 벌서 그들은 不具를 탄식하고만 잇슬 때 가 안이다. 그들도 완전한 지식을 엇고 완전한 사람이 되게 되엿다. 이제 點子二二字를 참고삼아 드러보련다! 조선에도 그들을 위하야 훌륭하고 고마운 기관의 설비가 잇슨지 오래 엿스니 이는 곳 서울 天然洞에 잇는 濟生院盲㗚部가 그것이

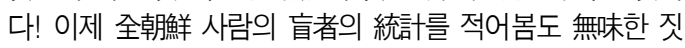
이 안일가한다. 數 적은 조선사람 중에 얼마나 만흔 사람이 光明을 못보고 어두움에서 우는 것을 보라. 숭朝鮮人의 亡ㅡㅂ 數는 1만1천85인이며 이것을 道別과 男女別로 보면 다음과 갓다. (再昨年 5 월 現在) 여자가 남자보다 소수인 것을 알 수 가 잇스나 그 원인은 물론 알기에 힘들 것이다. 또 욘⿶ㅆ소스로 보면 비교적 長壽者가 만흐며 調査에 의하면 80세 이상의 수명을 가진 사람이 204 人을 算한다. 그러고 대다수의 연령 은 36세 이상 40세 이하로 결국 중년에 속하는 健全한 일시 군이 될 사람이 만흔 것을 발견하엿다(Park, 1929).

위 인용문을 보면 조선시대 심청전을 예로 들면서 시 각장애자에 대한 의미를 언급하면서 점자(點字) 교육을 담당하는 제생원의 학교기능을 강조하고 있다. 아마도 당 시 특수교육은 언어장애보다도 시각장애에 대한 교육환 경에 관심을 보였던 것으로 판단된다. 더불어 1920년대 의 경우 시각 및 언어장애자 수도 1 만 1 천 85 인 정도라는 통계치도 제시되고 있어 정부 주도의 장애인 관리 체계도 형성된 것으로 보인다. 
이제 새 희망을 가지고 배호고저 하는 이의 입학과 졸업후의 직업을 소개하려 하며, 盲生科䠌生科가 잇스나 啞生部의 대한 것은 달니 소개하겟기 여기에 略하고 늡ㅇㄴ 만을 소개한다. 입학에는 특별한 시험은 업스나 건강에 대하 야는 조건을 부치고 엄밀한 검사를 하야 입학 후에도 不健康 한 상태를 발견하거나 성적이 劣等하야 장래의 희망이 업다 고 訒定하는 자에게는 부득이 퇴학을 식히는 수가 잇다 하 며, 연령은 특별한 제한이 업고 12세 이상이면 누구나 입학

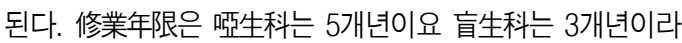
한다. 盲科에는 生徒의 연령이 대개 만흠으로 이해력이 양호 하야 修業年限이 3개년이라고 하지만 日語와 家科에 대한 技術의 연습에 주력을 함으로 제 1 학년 2학기에는 쉬운 대화 는 능히 할 수가 잇고 제 2 학년에서는 學科로는 銊按과 맛사 -지를 배호고 제 3 학년에 이르면 授業時間에 實地練習을 目 的하야 일반에 需應하야서 기술의 연습과 普通禮法의 實際 에 熟練하도록 한다. 呚授科目으로는 修身, 朝鮮語, 日語, 算術, 唱歌, 體操, 銊按맛사-지 等을 가르키며 주로 졸업후 의 직업을 위하야 기술을 가르킨다. 입학을 한 후에 넉넉히 自費로 통학을 할만한 사람이 못되면 給費의 制度가 잇서서 給費生은 전부 기숙사에 수용하야 食料와 用品을 주는 이외 에, 입학 퇴학 혹은 夏季休睱에 鄉里에 도라가는 사람에게는

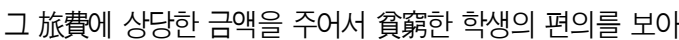
준다. 그러나 給費生이라고 졸업후에 무슨 의무가 잇는 것이 안이라 소었 救濟의 목적으로 수용한다고 한다. 昭和三年년 3 월말 현재의 給費生은 盲生이 23 人 啞生이 14 인이라 하며, 盲生의 현재 졸업생 중에는 總督府醫院과 道立病院에서「맛 사-지」技工으로 재직중에 잇는 사람이 4人인 바, 月額이 38圓 이상 40圓이나 되고 근무후에 自宅에서도 10數圓의 收入을 어들 수가 잇고 또 都市에서 自營하는 자는 월수입 30圓으로 80圓까지나 되여서 상당한 생활을 하는 사람이 만 코 呚職에 從事하는 사람도 잇다고 한다(Park, 1929).

위의 인용문을 통해 초기 제생원에는 12 세 이상 20 세 까지의 맹아자가 입학할 수 있었으며, 별도의 시험은 없 으나 입학 후에 학교를 다닐 건강상태가 아니거나 성적이 불량한 자에게는 부득이하게 퇴학 되었다. 이러한 조치는 당시에 학비 및 생활비를 일부 지원해줄 정도로 복지 여 건이 우수했던 것으로 보인다. 수업내용은 보통학교의 수 신, 일본어, 조선어, 한문, 산술, 이과, 창가, 체조, 침술 과 마사지(銊按), 등의 교과목을 운영하였는데 특이할 만 것은 교육과정 내용에 체조(體操) 교과목이 포함되었고 이것이 장애인체육의 시초인 것으로 판단된다. 기존 학계 논의는 6.25 와 베트남 전쟁에서 상해를 입은 상이군경, 특히 척수손상자와 1950년대와 1960년대에 많이 발병 한 소아마비(척수회백수염)자의 재활, 복지 및 체육활동 을 지원하는 것에서 출발한다는 일부 견해가 있지만
(Kim \& Je Kal, 2014; Han, 1996; Hwang, 2014), 실 제로 이전에도 장애인체육이 존재한 것이다.

또한, 지금의 스포츠마사지로 일컫는 안마(銊按) 기술 이 일제 강점기에 처음 교과과정에 도입되기도 한다. 아 마도 체조는 학교의 교실 또는 체육관에서 기초체력을 배 양하기 위한 수단이었으며 마사지는 장애인들의 생업을 위한 교육이었다. 그 이유는 전자의 경우 “체조는 신체의 각부(各部)를 균제(均齊)케 하여 자세를 단정히 하고 정 신을 쾌활케 하며 겸(萧)하여 규율을 수(守)하고 절제(節 制)를 숭상(崇向)하는 습관을 양(養)함을 요지로 하는 데 있으며 (Joseon Government General, 1918), 후자 의 경우는 위 내용에 총독부 산하병원 및 각 도립병원에 “맛사지 技工”으로 재직하고 있음을 밝힌 데서 확인될 수 있다.

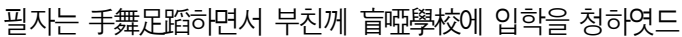
니 즉시 허락을 하심으로 京城府 西大門外의 濟生院盲啞部 에 입학하야 4년 修了하고 再次 일본에 東京龔啞學校高等部 를 졸업하야 지금은 타인과 如何한 筆談이든지 용이함을 歡 홈한다. 然이나 조선에서는 壟咧社會를 위하야 如何한 직업 에 취직할 기관이 無함을 유감으로 아는 바요, 만일 壟啞者

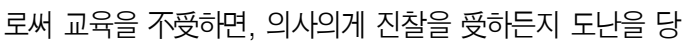
할 時나 혹은 경찰서에 如何한 관계가 有하든지 裁判等이 有

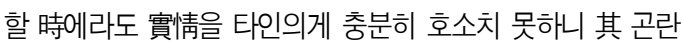
과 실패를 感하는 涇 本人과 其親族의 心痛은 형언키 難하니 실로 가련하고 한심하다(Kim, 1929).

하지만, 1929년 당시의 장애인 처우에 대한 사회 분위 기는 그리 좋지 않았던 것으로 보인다. 위 인용문으로 보 아 당시 제생원을 수료한 자의 경험담으로 볼 때 일본 동 경에 소재한 특수학교를 다시 입학하면서 당시 한국 장애 인의 경우 취직할 기관이 없으며 경찰서와 같은 관공서에 서의 장애인 처우의 열악함을 호소한 상황 사례를 본다면 확인될 수 있다.

제생원 체육활동은 여러 가지 한계를 보였는데 주로 체육지식, 시설 또는 도구, 지도 교사 등의 교육환경이 갖 추어져 있지 못하였던 것 같다. 체육은 단지 학교 교육과 정의 필수 교과로서 체조 교과가 있어서 신체활동이 이루 어지고 있었으나 오늘날과 같은 정식 경기를 할 수 있는 여건을 갖추지 못하였기 때문에 학생들 주도로 개별적 놀 이형태의 체육을 즐길 수밖에 없었다(Ministry of Culture \& Tourism, 2007). 


\section{해방이후 특수학교 체육교과과정 분석}

1945년 해방 이후 제생원은 국립맹아학교로 명칭이 변경되고 1946년부터 당시 초등학교와 동등한 수준의 6 년제로 변경되면서 교육과정이 심화된다(Dongailbo Newspaper, 1946; Lee, 1990). 초기 맹아학교 현황과 관련된 내용은 다음에서 나타난다.

인왕산 밑에 안윽히 자리잡고 있는 국립맹아학교(國立盲齍 學校) 정문에 들어섰습니다. 운동장이라기보다 정원(庭園) 이라는 느낌을 주는 교정(校庭) 이곳저곳에 남녀 아동들이 명랑 경쾌하게 뛰놀고 있섰읍니다. 그러나 도무지 떠드는 소 리가 들리지 안습니다. 마치 무성영화(無聲映畫) 보는 듯 그 러니까 이 애들은 아생(咧生)인 것이였습니다. 사무실을 안 내해 달라고 그중에서 큰아이에게 말로하였드니 그애는 알 어채리고 기자에게 따라오라는 것을 손짓으로 표시하였습니 다. 마침 점심시간이라 교장선생은 자리에 없다는 것이 었읍 니다. 교수참관도 좀기다려야 된다는 것이었습니다. 기자는 기다리는 사이에 서무(庶務) 보는 선생에게서와 그학교에 + 프년 근속하여 근속하여 맹아생 (盳啞生)의 아버지라 일컽으

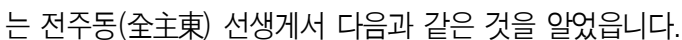
즉 재적아동수(在籍兒童數)는 三百六十品인데 맹생(盳生)아 국민과(國民科) 二十一명 중등과(中等科) 二十九명이고 아 생(啞生)이 국민과(國民科) 二백 四十品 중등과(中等科) 三 +명으로 三백명이 된다고 합니다. ‥(중략)... "졸업한 뒤 의 직업상황(職業常況) 또는 결혼생활(結婚生活)은 어떻습 니까?" “직업과(職業科)로 맹생(盳生)에게 침안과(鍼按 科) 아생(啞生)에게 양복재단(洋服裁斷) 공예과(工藝科)를 교수하고 있는데 졸업 후 침술(金威術)과 안마(按摩)의 허가를 얻어가지고 수입이 상당한 맹생도 있고 재단공예로 경제적 여유가 있는 아생(㕶生) 도 많습니다. 결혼은 아생(啞生)은 아생끼리 하는 예가 많은데 아주 원만하게 지내고 있고 자녀 도 많이 길읍니다. 맹생은 대개가 보통사람과 결혼하고 있읍 니다. " …(중략)... 운동장에는 아생중등부(啞生中等部)의 건장하게 생긴 청년들이 묵묵히 체조를 하고 있읍니다. 또 저쪽 철봉들이 있는 편에는 아마 아생중등부 여학생인 것 같 은 제복입은 - 대가 율동유희(律動遊戲)를 하고 있습니다 (Kyunghyang Shinmun Newspaper, 1948).

위 인용문을 통해 당시 재적수는 360 명으로 시각장애 학생 중 국민과(國民科) 21 명 중등과(中等科) 29 명이고, 언어장애 학생이 국민과(國民科) 240 명 중등과(中等科) 30 명 정도로 비교적 언어장애 학생이 많은 것으로 나타 났으며, 주 교육은 장애인의 직업으로 의미 있는 침술과 마사지 (안마) 중심의 직업훈련이었다. 다만, 위 내용에서 도 보듯이 1948년 국립맹아학교는 일반학교와 유사한 체
육이 시행된 것으로 보이나 특징적으로 남학생은 기계체 조를, 여학생의 경우는 단체 도수체조를 주로 시행한 것 으로 보인다.

이러한 장애인 학교운영은 1959년에 국립맹학교와 국 립농학교로 각각 분리되었고 1958년부터는 장애인에 대 한 배려와 국내 정세의 변화에 다른 교육과정 개정 필요 성을 인식하고 학제를 개편하게 된다. 1963년엔 특수학 교가 없는 도(道)에서 최소 1 개 이상의 학교를 개설하게 되며 1967년에 초등부는 주당 보건 2시간, 중등부는 주 당 체육 3시간을 배정시킴으로 특수학교 체육교육이 체 계를 갖추기 시작했다(Ministry of Education, 1967; Jung, 2004).

한편, 초기 맹학교와 농학교의 교육과정은 체육 운영 상의 특징을 확인할 수 있는 단초를 제공해 준다. 먼저, 맹학교 초등부는 (1) 정서 안정, (2) 보행 및 점자 습득력 배양, (3) 사회 적응력, (4) 시력 개발, (5) 신체기능 보호 및 예방, 중학부는 (1) 직업 기능력 신장, (2) 진로 및 자활 능 력 배양, (3) 사회성 배양, (4) 신체기능 활용 및 보호, 그리 고 고등부는 (1) 인생관 정립, (2) 품성 배양, (3) 자립적 생 활 영위 등으로 구성되어 있다. 농학교의 초등부는 (1) 구 김살 없는 품성, (2) 언어 사고력, (3) 사회 적응력, (4) 잔존 청력 활용, (5) 신체기능 보호 대책 강구, 중학부는 (1) 직 업 사회 지식과 기능 및 근로 존중 태도, (2) 장래 진로 선 택 자활 능력, (3) 기초 학력 충실, (4) 안전 교육 강화, 기 능 활용보존 능력, 고등부는 (1) 건전한 인생관 확립, (2) 사회 헌신 태도, (3) 자립 생활 영위 능력 등을 제시하고 있다(Ministry of Education, 1967; Shin, 2004).

위 항목을 살펴보면 초.중등부까지는 신체능력 배양에 초점을 맞추고 있으나 반면에 고등부는 취업 소양을 강조 하고 있다. 따라서 앞서 언급한 초등부 주당 보건 2시간, 중등부는 주당 체육 3 시간 배정은 초·중등부에 공통적으 로 나타난 “신체기능 보호”라는 항목과 연계되어 교육목표 가 설정된 것으로 판단된다.

1950 60년대의 특수학교 체육은 일반학교 교육내용 을 준용하면서 장애인체육 별도의 교재가 없었기 때문에 체육교사가 특수학교에서의 체육의 특징은 일반학교 보 건, 체육 교육내용을 그대로 적용하였다. 즉, 장애학생 체 육활동의 특색이 잘 나타나지 못한 과도기적 측면을 보였 다(Ministry of Education, 1967; Ministry of Culture 
\& Tourism, 2007).

특히, 당시 특수학교는 일반학교와 유사하게 초등부의 경우 보건을 중고등부는 체육을 실시하였는데, 1970년 대에 들어와 초등부의 경우 1967 년에 제정 교육과정 배 당 기준보다 체육(보건)이 하향 조정되었다. 이 같은 경 향은 1960년대에 비해 교과목의 수가 늘어남에 따라 나 타난 현상으로 보인다(Ministry of Education, 1974; Jung, 2004).

1980년대는 초등부의 경우 즐거운 생활(체육, 음악, 미술) 중 1,2 학년 각 2 시간, 체육 3 6학년 각 1 시간이 감소하였다. 이는 장애의 개선과 극복을 위해 각 학년 2 시간 이상 재활 훈련으로 대체·운영하기 위한 조치라 할 수 있다. 중등부 역시 장애 학생의 의료적, 심리적, 교육 적, 직업적 재활의 도모를 통한 올바른 인간상 정립을 위 해 재활 훈련 영역을 신설하여 편성하여 체육이 축소 편 성하였으며, 고등부 경우는 체육과 교련이 통합 운영되었 다(Ministry of Education, 1983; Jung, 2004). 초중 고등부 교육과정은 점차로 일반 교육과정의 교과목을 그 대로 적용되어 체육 시간이 축소된 경향을 보였으며 반대 로 재활 훈련 활동 및 학교 재량 시간이 확대 된다 (Ministry of Education, 1987a, 1987b, 1988; Jung, 2004).

1990년대는 체육과 별도로 특수체육 교과목이 등장한 시기이다. 특히, 지체부자유 학생을 위한 특수체육이 강 조된다. 특수체육 운영의 핵심은 체육 실기 면에서 지체 장애인이 즐길 수 있고 체육 이론면에서 장애인체육 발달 과정과 패럴림픽에 대한 부분을 보완하며 지체장애인들 의 보장구 사용 및 관리방법, 정기적인 진단과 교정치료, 예방대책 등을 제시하고 있다(Ministry of Education, 1998; Jung, 2004).

종합적으로 살펴보면, 1940 50년대 특수학교와 체 육교과 운영은 이전 제생원 수준의 운영 및 체조 중심의 체육이 시행되었으나, 1960년대 이르러 장애인 특성별 학교가 서울을 비롯한 각 시도로 분산 운영되는 교육 환 경 변화가 나타나지만 일반학교 수준에 국한된 체육 운영 의 제도적 기틀이 마련된다. 1970 년대는 교과목 수의 증 가로 인해 장애인체육 시간이 축소되었고 1980년대는 장 애인별 자활능력이 중점화됨에 따라 상대적으로 체육 시 간이 축소되었고 1990 년대 들어서 본격적으로 일반학교
와 유사한 체육교과와 차별되어 지치장애 중심의 특수체 육 교과가 신설됨에 따라 장애인 맞춤식 교육처방이 제시 된다. 1990년대에 들어 특수체육이 신설된 이유는 아마 도 1988년 서울올림픽 개최에 따른 국내 체육 선진화 분 위기 속에서 장애인 체육인프라도 성장된 것에서 비롯된 것이다. 뒤이어 1988년 대학교에 특수체육 전공 신설과 함께 1990년 특수체육교사 제도 도입은 이를 증명할 수 있는 사례일 것이다((Ministry of Culture, Sports and Tourism, 2018; Hwang, 2014).

\section{시대별 장애인체육 활동의 변천과정}

\section{0년대 장애인체육의 활동과 변화}

1960년대는 학교체육 환경의 열악함으로 장애인에 적 합하게 수정한 놀이형태 체육에서의 의미를 보였으며 주 로 시각장애 학생에게서 독특한 방식의 체육 형태가 나타 났다. 주로 시각장애 학생들은 라디오를 듣고 중계되는 야구, 축구를 자신들에게 적합하게 변형한 것이다(Choi, 2016). 다음 자료는 시각장애 학생의 체육의 일면을 단 편적으로 확인할 수 있다.

유달리 발달한 청각과 촉각은 서울맹학교의 휴식시간에 더욱
약여하다. 철봉이나 수평을 하는 것은 보통이고 탁구까지 친
다. 공과 배터는 일반이 쓰는 것과 같지만 탁구대의 가운데
가 경계선으로 경사를 이루고 있어 공을 굴려서 이고개를 넘
기도록 되어있다. 공이 굴러오면 그 소리로 방향을 알고 배
터를 들이대에 공을 밀어넘기는 품이 눈 뜬 사람보다 정확하
다. 이밖에 축구볼만한 공을 굴려서 치는 야구, 땅으로 깔아
서만 차는 축구등 모든 감각을 시각대신 활용하는 이들의 의
지는 대단하다(Kyunghyang Shinmun Newspaper, 1969).

위 인용문을 본다면 비교적 시각장애자는 촉각과 청각 에 집중될 수밖에 없어 체육 환경도 그에 적합한 형태이 어야 한다. 위 내용에서 보면 경사를 이용한 공의 굴림소 리, 지면 마찰력을 활용하여 구기 종목을 운영하고 있다. 예를 들면 실내에서의 공간감을 활용한'방에서 하는 야구' 라는 말을 줄여서 '방야'가 학생들 사이에 유행하였고 공 의 위치를 확인하기 위해 축구공 대신에 플라스틱 돼지저 금통에 돌을 넣어 구를 때 나는 소리를 듣던지 깡통으로 
축구와 유사한 경기를 진행한 것이다(Choi, 2016; Ministry of Culture \& Tourism, 2007).

환경과 지도자 부족으로 장애인들이 정식적인 구기 종 목을 즐길 수 없었던 것에 반하여 유도는 일찍부터 학생들 에게 보급된 종목이었다. 유도는 1968년 국립맹학교에서 전교 학생이 대부분 수련하고 선수도 양성되는 체계를 갖 추기 시작했고(Kyunghyang Shinmun Newspaper, 1970), 이러한 분위기에 힘입어 1969년 일반인과 함께 하는 맹인시범유도대회가 개최되기도 하였다(Dongailbo Newspaper, 1973). 이같이 투기종목인 유도가 장애학 생에게 빠르게 정착된 것은 구기 종목과 비교하면 근접하 여 상대를 잡아 넘기를 운동이므로 거리에 대한 장점이 나름의 효과를 본 것 같다.

한편, 청각장애 학생들은 시각장애 학생보다 체육활동 의 제한점이 적어 다양한 종목에 참여하였다. 청각장애 학생 교육을 위한 국립서울농학교에서는 축구부, 농구 부, 유도부, 배구부, 씨름부 등의 운동부를 운영하였으며 (Ministry of Culture \& Tourism, 2007), 배구의 경우 에는 1962년 제43회 전국체육대회에 참가하여 일반 중 학교와 맞붙어도 손색이 없는 경기를 한 바 있다.

벙어리란 숙명적인 「핸디캡」때문에 모든 인간 대열에의 참 여를 스스로 체념해 버렸던 과거를 청산하기 위해 국립농아 학교 학생들은 감연히 힘과 힘을 겨루는 운동장으로 진출하 기 시작했다. "벙어리가 운동한다." 있을 수 있는 일이지만 얼핏 납득이 가지 않는 이러한 사고방식을 이들은 실력으로 극복하고 누구보다도 못지 않는 「스포츠맨 것을 만천하에 공개했다. 21 일 상오 서울운동장에서 거행된 제43회 전국체육대회 서울지구예선전에서 처녀출전한 국립 농아학교배구 「팀」 은 말없는 1시간여의 치열한 공방전 끝에 배구의 명문 京東중학「팀」을 2대0「스트레이트」의 압도적 인 「스코아」로 물리쳐 관중을 놀라게 했다. 말이 통하지 않 는 선수들은 작전 「싸인」을 손짓발짓으로 전달하며 놀라운 「팀웍」과 운동신경을과시하여 「게임」을 시종 「리드」 한 것이 다(Dongailbo Newspaper, 1962).

위 인용문을 본다면 당시 사회적 분위기는 장애인이 체육을 하는 것이 일반적이지 못했던 것 같다. 그런데도 1962년 전국규모의 배구경기에서 일반중학교에 승리를 거둔 것은 매우 흥미로운 사례이다. 아래 사진은 당시 배 구 경기에서 언어장애 학생을 대상으로 지도자가 열떤 설 명을 하는 과정을 보여주고 있다. 지도자가 수화 및 다양
한 손짓발짓을 전달하며 일반학생에게 승리한 것은 지도 자 노력은 물론 당시 학생들의 협동과 초인적 운동신경 등이 조화롭게 적용된 사례로 볼 수 있겠다.

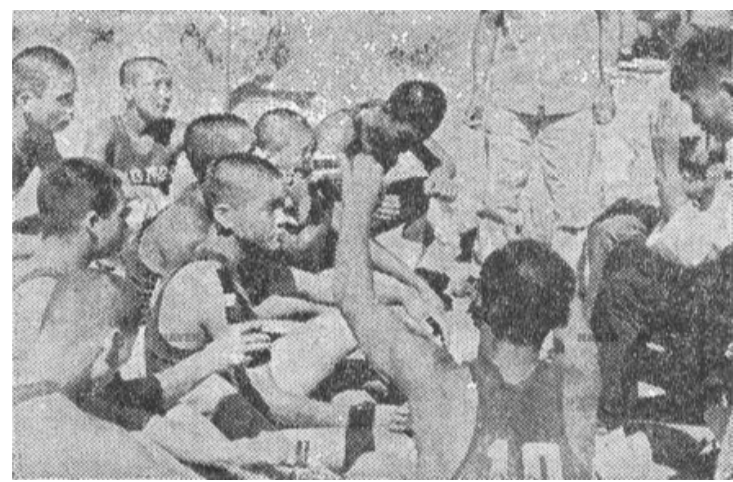

Fig. 2. Deaf Students Coaching Scenes After Volleyball Operation Time(Dongailbo Newspaper, 1962)

이처럼 1960년대는 특수교육을 하기에 지극히 열악한 환경에서도 장애인학교를 중심으로 체육활동이 활발히 전개할 수 있는 동력을 마련한 시기로 볼 수 있었다. 특 히, 장애학생도 일반인과 함께 충분히 체육을 할 수 있다 는 분위기를 사회적으로 보여준 계기를 마련하기도 한다.

\section{0년대 장애인체육의 활동과 변화}

1970년대도 1960년대와 유사하게 구기 및 투기 종목 별 체육활동이 더욱 활기를 띈 시기였다. 시각장애 학생 의 탁구경기는 1960 년대 방식과 같이 구기 종목을 운영 하였는데 일반인 기준과 달랐다.

아무것도 볼 수 없는 맹인학생들이 공을 차고 탁구를 하고 야 구경기도 한다. 스트라이크 볼 투앤투 의자에 앉은 캐쳐가 타 자의 스윙과 볼의 굴러가는 방향을 눈으로 보듯, 정확히 말한 다. 十六일 오후 서울 종로區 신교洞 국립서울맹학교(교장 沈 暻览. 五一)의 고-학년 -반 학생 + 七명은 운동장에서 체육 복을 입고 야구시합에 열을 올리고 있었다. 손벽을 쳐 사인을 보내는 캐쳐가 피처에게 "다음은 표번 타자 수ㅇㅛㅛ진이다. 직구 를 넣어”하고 말하자 二루에 나가있던 裴학진군(二-)이 “큰 것 하나 때려”라고 응원 공수간에 열을 올렸다. $\cdots$ (중략) $\cdots$ 경기규칙은 일반인과 똑같으나 볼이 야구공 대신 축구공이며 피쳐가 볼을 굴려 의자에 발을 벌리고 앉아있는 캐처의 발사 이로 들어보내면 스트라익이고 밖으로 굴러나가면 볼이다. 
또한 배이스에서는 손벽을 쳐 러너에게 위치를 알려주고 타자 가 친공을 잡는 수비측에게도 알려준다. 맹인들이기 때문에 역시 시간이 많이 결려 회수는 대개 표회 정도, 한번 출루하 면 홈인을 하기 쉬워 점수는 $七$, 서점 가량 난다는 것. 이들이 하는 축구는 골포스트 없이 가로 三十五m 세로 四十m의 작 은 운동장에서 표 十명이 한팀이 되어 상대편 골라인을 넘으 면 골인되는 약식이다. 볼은 플라스틱 튜브안에 모래와 자갈 쇠붙이를 넣어 굴러가면 소리를 내게 만들어진다. 탁구의 경 우만은 공과 배트가 일반인 것과 똑같고 경기규칙도 같은데 탁구대만 다르다. 네트 대신 네트 치는 곳을 중심으로 +一五도 각도로 경사지게 하고 공이 땅에 떨어지지 않게 탁구대 가장 자리 판자에 맞기전에 상대편 쪽으로 굴려넘겨야 하며 탁구대 밖으로 나가거나 판자에 맞으면 아웃으로 간주, 점수를 잃는 다(Dongailbo Newspaper, 1973).

보통 야구는 일종의 발야구 변형으로 야구배트로 축구 공을 활용하여 진행되며 점수폭을 줄여 시간 경과율을 줄 였으며 축구는 작은 공간에서 그룹별 조를 형성하여 쉽게 골인할 수 있도록 규정을 변화시켰다. 아래 그림을 보면 당시 변형된 야구 형태를 확인할 수 있는데 공은 축구공 형태로 부피가 비교적 크며 손뼉을 쳐서 사인을 보내는 캐쳐는 의자에 발을 벌여 앉아있는 형태로 일반 야구 형 태와는 사뭇 다른 형태를 보였다.

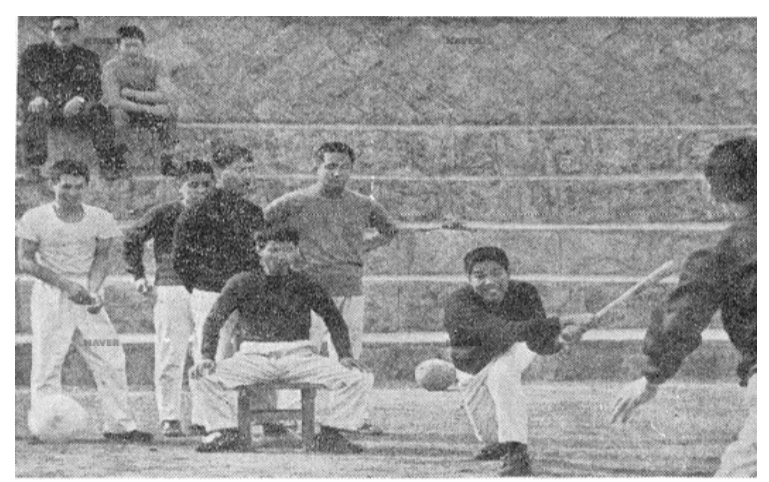

Fig. 3. Baseball Scenes of the Blind Student in Seoul (Dongailbo Newspaper, 1973)

탁구도 경사진 탁구대를 활용하여 공이 구르는 소리를 듣고 네트 밑으로 공을 상대에게 보내는 경기 형태였다. 1960년대와 같이 야구와 축구는 놀이형태를 보였던 것에 반해 탁구는 공식적 대회가 개최되기도 하였다. 당시 탁 구 인기는 서울맹학교동창회 및 은행(서울신탁은행) 등 의 후원으로 1974 년에 전국맹인탁구대회를 진행하기도
했다(Ministry of Culture \& Tourism, 2007). 한편, 시 각장애 유도 경기는 1969년 이후로 1971년에 제1회 맹 인소년유도대회가 개최되며 1972년에는 지방 순회 대회도 진행되었다(Kyunghyang Shinmun Newspaper, 1971).

청각장애 학생의 경우도 1960 년대와 유사하게 왕성한 활동을 벌여 1975 년에 이르러 제1회 한국사회사업대학 (대구대학교) 총장기 타기 전국 농아학교 체육대회가 개 최되어 장애인 단독 체육대회를 개최하기에 이른다 (Choi, 2016). 보통 이전까지는 일반인 체 육대회에서 시 범 경기 성향이 있었던 것에 비하면 놀라운 성과로 볼 수 있다.

이밖에도 1970 년대부터는 시각, 청각은 물론 지체장 애와 관련된 국제적 친선대회가 개최되기에 이른다. 국제 적 체육 교류의 첫 국가는 일본이었다. 중요 종목은 시각 장애부유도, 탁구, 야구, 달리기 $(60 \mathrm{~m})$, 지체장애부 휠체 어달리기, 휠체어탁구, 휠체어투포환, 투창, 언어장애부 달리기 $(100 \mathrm{~m}, 200 \mathrm{~m})$, 높이뛰기, 투포환, 체조 등이 었 다. 문제는 국내 자체로 정한 경기규칙 때문에 혼선을 겪 는 현상이 보여졌다. 예를 들면 야구는 방울이 달린 야구 공이 있으나 축구공으로 활용하였고, 탁구대 규격도 달라 국제경기에 대비한 여력이 부족했다(Kyunghyang Shinmun Newspaper, 1973).

1970년대의 장애인체육도 특수학교를 중심으로 한 체 육이었다. 특이한 것은 장애인 중심의 종목별 대회가 결 성되었고 이와 아울러 국제적 체육 교류도 나타나기 시작 했다는 점이다. 아쉬웠던 점은 국제 표준의 체육이라기보 다 환경의 열악함으로 인해 자구적 성향의 놀이 체육 성 향에서 벗어나지 못한 면이 존재했다.

\section{0년대 장애인체육의 활동과 변화}

1980년대는 한국 체육사에서 중요한 이슈였던 88서 울올림픽이 개회된 시기로 장애인체육에서도 획기적 성 과를 보였다. 이 당시부터 한국은 국제적 체육 환경변화 에 능동적 대처를 하기 시작하였고 장애인체육에 대한 관 리에 있어서도 국제적 기준에 부합하려는 노력을 아끼지 않았다. 1981년은 UN이 제정한세계 장애인의 해'로서 국내에서는 이를 계기로 장애인에게서의 교육, 복지 등 사회 전반을 평가하고 관련 행사를 개최한다(Ministry of Culture \& Tourism, 2007). 
한편 국내 장애인체육 개선의 일환으로 개최한 1981 년 제 1 회 전국장애인체육대회는 시각장애, 지체장애, 청 각장애, 정신지체 (지적장애) 등 다수의 장애 영역의 선수 들이 역도, 유도, 맹인탁구, 수영, 육상 등 5개 종목에 참 가하였다. 육상경기에서는 시각장애의 경우 $60 \mathrm{~m}$ 를 줄에 매단 배턴을 잡고 달리기를 하던지, 지체장애는 휠체어 마라톤 $(10 \mathrm{~km})$ 과 투포환이 선보여졌고 전국장애인체육 대회를 계기로 종목별 경기들은 국제규격에 준하여 진행 하여 국제대회 참가가 가능할 수 있는 체계적 체육 경기 의 변화가 나타난다(Dongailbo Newspaper, 1981).

1980년대는 장애인을 위한 조직 및 체육시설이 마련 되는 시기이기도 하였다. 1988 년 서울패럴림픽 개최를 위하여 조직위원회가 결성된 이래로 한국장애인복지체 육회가 별도의 조직으로 설립된다(Seoul Economic Newspaper, 2010). 이러한 장애인 특수조직이 형성되 면서 장애인과 일반인들이 함께 사용하므로 사회통합을 이룰 수 있는 여건 조성 프로그램을 운영하기 시작하는데 예를 들면 장애인 국토순례 캠프를 운영할 때 일반인도 함께 참여할 수 있는 체육대회도 개최되기 시작한다 (Hankyoreh newspaper, 1987).

한편, 1980년대는 다양한 국제 장애인체육대회에 참 가하는 계기를 마련한다. 이전까지는 국제대회 규칙과 다 른 형식의 놀이형 체육을 하였지만, 장애인체육과 관련 전문가들의 지원으로 국제 종목규칙에 따른 장애인체육 이 활성화됨에 따라 1984년 한국은 6월 1일에 국제농아 인스포츠위원회(CISS, Comite International Des Sports Des Sourds) 가입 후 최초로 1985년 7월 제15회 세계농아체육대회(미국 로스앤젤레스)로 육상, 사이클, 탁구 등 3개 종목에 선수가 참가하게 된다(Choi, 2016; Ministry of Culture \& Tourism, 2007).

1980년대를 종합적으로 확인하면 장애인체육은 이전 의 특수학교 중심의 체육에서 벗어나 정부 주도의 정책변 화로 그 범위가 확대된다. 특히, 88 서울올림픽 개최는 장 애인체육의 기틀을 갖추는 제도, 조직, 시설을 갖추게 한 계기를 주었으며 궁극적으로 장애인에게 체육은 재활 의 옥을 높이기 위한 도구일 뿐만 아니라 삶의 한 일부분으 로 인식하는 상징적 의미를 제공하였다(Cho \& Gu, 2006; Hwang, 2014; Kim \& Je Kal, 2014).

\section{0 년대 장애인체육의 활동과 변화}

1990년대의 장애인체육은 일반 생활체육의 활성화와 함께 사회적 소수자에 대한 복지 증진 추세에 따라 세부 영역까지 진화 발전한다. 예를 들면 장애에 따른 세부 대 회 운영과정이 달라져 시각장애의 경우 전맹과 약시를 구 분하여 운영하는 경기(탁구)로 세분화되며 기존의 정부 및 단체 주도형의 대회 개최방식에서 후원사로부터 기금 을 지원받아 대회를 개최하게 된다(Cho \& Gu, 2006; Hwang, 2014). 아울러 국제적 입지도 강화되어 1984년 국제농아인스포츠위원회(CISS) 가입 후 1993년 총회에 서 70년 역사상 동양인으로서는 처음으로 집행위원으로 선출되어 우리나라의 국력과 위상을 나타내었다 $(\mathrm{Cho} \&$ $\mathrm{Gu}, 2006)$.

1990 년대의 가장 의미 있는 발전은 장애인체육의 학 문적 발전이었다. 1988년 처음으로 장애인체육 전공이 대학에 마련되어 1990년 장애인체육교사자격이 신설되 고 장애인생활체육지도자는 1993년부터 신설되어 별도 의 자격검정을 위해 16 개 시도 생활체육지도자를 대상으 로 지도자 강습회를 열어 장애인 특성에 따른 체육프로그 램을 소개하게 된다. 이에 따라 일반체육 지도자가 장애 인체육 지도도 병행하는 방식에서 벗어나 특수학교는 물 론 생활체육 분야에서도 전문지도자가 배출된다. 또한, 특수체육학회가 결성되어 장애인체육의 교육뿐만 아니 라 학문적 영역 기반도 형성된 것이다(Hwang, 2014; Ministry of Culture, Sports and Tourism, 2018).

\section{0년대 장애인체육의 활동과 변화}

2000년대의 장애인체육은 법적 토대 구축은 물론 장 애인의 복지 여건의 신장을 중심으로 볼 수 있다. 즉, 1980 90년대의 장애인체육은 양적 성장을 효율적으로 관리하기 위한 교육 및 학문체계 구축에 치중된 경향으로 국가 중추적 체육이라는 측면의 전문성에서 부족한 면을 보였다.

이에 따라 정부는 2005년 국민체육진흥법 개정을 통해 장애인체육에 관한 법·제도적 기반을 마련하여 많은 장애 인이 운동을 즐기고 활기찬 삶을 영위할 수 있는 환경을 조성한다. 더불어 같은 해의 대한장애인체육회 설립은 장 
애인 엘리트체육 및 생활체육 활성화를 위한 꿈나무선수 발굴 육성, 경기단체·시도지부 육성 및 지원 등을 도모해 왔으며, 아울러 국제 패럴림픽 (쟁애인올림픽)위원회와 경 기단체의 가교 역할을 하는데 기여하였다(Ministry of Culture, Sports and Tourism, 2018).

특히, 이 시기부터 장애인체육 경기운영 분야는 새로 운 발전이 시작되어 전국장애인체육대회 순회개최가 이 루어진 것이다. 이러한 개최방식은 개최지 시민들의 장애 인체육에 대한 인식을 개선시키고 장애인 생활체육 활성 화와 편의시설을 확충시키는 데 결정적 기여를 하게 된다 (Lee, 2010).

따라서, 2000년대는 이전과 달리 시설, 제도 등 장애 인체육 기반마련은 물론 장애인권익 보호 및 체육참여 여 건도 개선된다. 특히, 장애인체육 전문 상담사 신설로 장 애인체육에 대한 불공정에 대한 민원 해결 환경이 조성되 었고 공공체육시설 장애인 편의시설 및 체육시설 설치 의 무화를 추진하여 장애인도 일반인과 동등한 체육참여 기 회를 마련하는 시기이기도 하다(Ministry of Culture, Sports and Tourism, 2018; Seoul Economic Newspaper, 2010).

\section{결 론}

본 연구는 특수학교 의 체육교과 변화와 한국 장애인 체육 환경이 어떻게 변화해왔는지에 대한 과정을 심층적 으로 파악하는 것이다. 이에 대한 종합적인 결론은 다음 과 같다.

먼저, 특수학교와 체육 교과목 운영의 변천 과정은 다 음과 같다. 1940 50년대 특수학교는 해방 전 제생원 수 준의 학교운영에 머물러 체육은 체조 중심으로 시행되었 으나, 1960년대 이르러 장애인 특성별 학교가 설치되어 지역적으로 분산 운영되는 발전을 보였고 체육 교과도 제 도적 기반을 조성했으나 일반학교 체육교과 운영 측면을 보였다는 것에 한계를 보였다. 1970 80년대는 교과 수 및 장애인별 자활능력이 중점화됨에 따라 장애인체육 시 간이 축소되었다. 1990년대 들어서 본격적으로 일반학 교와 유사한 체육수업과 별도로 지치장애 중심의 특수체 육 교과가 신설됨에 따라 맞춤식 장애인 학생 운동처방이
시행된다. 특수체육이 신설된 이유는 1988년 서울올림 픽과 서울패럴림픽 개최에 따른 국내 장애인 체육 인프라 의 급속한 성장에서 비롯된 것이다.

다음으로, 시대별 장애인체육 운영 및 환경 변화과정 을 확인하면 다음과 같다. 1960년대는 열악한 장애학생 체육환경으로 인해 정규 체육수업보다 놀이 성향의 체육 활동이 활발히 전개되는 시기였다. 1970년대 장애인체 육은 종목별 대회가 결성되었고 국제 체육교류도 처음 시 도되었다. 1960 70년대는 주로 특수학교 중심의 체육 활동이 주류였던 것에 반하여 1980년대 장애인체육은 정 부 주도로 수혜 대상의 범위가 확대된다. 특히, 88서울올 림픽 개최로 인해 학생은 물론 성인 장애인체육의 기틀을 갖추는 제도, 조직, 시설을 갖추어 궁극적으로 장애인에 게 체육은 재활 도구일 뿐만 아니라 삶의 한 일부분으로 인식되기에 이르렀다. 1990 년대의 장애인체육은 학문적 발전성과를 보였다는 점에서 의미를 보였으며 2000년대 의 장애인체육은 1980 년대의 양적 성장과 1990 년대의 학문적 토대를 바탕으로 법적 토대 구축은 물론 장애인의 복지 여건의 개선을 이루게 된다.

일제 강점기부터의 특수학교를 중심으로 발전된 장애 인체 육은 1980년 이전까지 특수학교 중심의 체육활동이 주류였으나 1980년대 급속한 체육 전반의 양적 성장과 장애인의 사회참여와 욕구충족에 대한 권익 상승으로 인 해 국가 주도형 체육 영역으로 부각되고 있다. 앞서의 변 천과정을 참고하여 미래에는 장애인에게 있어 신체활동 을 통해 얻어지는 체육의 가치를 보다 합리적으로 해결할 방안을 모색하길 바라마지 않는다.

\section{참고문헌}

Cho, C. O., Oh, A. R., Jang, J. H.(2012). The Present State and of Changing Process of Disabled Sports in Laws -Focusing on the National Sports Promotion Act-. Journal of Sports Entertainment Law 15(4), 119-139.

Cho, C. O., Gu, K. M.,(2006). Sports for the Disabled in Accordance with Historical Approach. Journal of Sport and Leisure Studies 27, 391-406.

Choi, J. S.(2016). A Study on the Activation Plan of Disabled Sports. Master Degree. Department of Public Administration 
Graduate School of Public Administration at Yeungnam University.

Choi, S. G.(2018). Adapted Physical Education. Rainbowbooks Press.

Choi, S. G.(2006). The Developmental Suggestions for the Enhancement of the Korea National Games for the People with Disabilities. Korean Journal of Adapted Physical Activity. 14(3), 1-19.

Dongailbo Newspaper(1946). March 21.

Dongailbo Newspaper(1962). September 21.

Dongailbo Newspaper(1973). February 17.

Dongailbo Newspaper(1981). September 8.

Hankyoreh newspaper(1987). July 15.

Han, M. K.(1996). Development of the Sports for the Disabled in Korea. Korean Journal of Adapted Physical Activity. 4(1), 183-198.

Hwang, S. H.(2014). Historical Transformation and Characteristics of Disability Sport in Korea. Master Degree. The graduate school of Physical Education at Korea National Sport University.

Joseon Government General (1911). General Gazette. June 21.

Joseon Government General(1912). General Gazette. March 28.

Joseon Government General(1918). Decree 97. General School Rules 14.

Jung, H. Y.(2004). Study on the history of special school curriculum in Korea. Master Degree. Department of Elementary Special Education. The graduate school of Education at Dankuk University. 1-52.

Kim, T. H., Je Kal, Y. S.(2014). History of the Field of Adapted Physical Education in Korea and the Future Messages. Journal of Exercise and Sport Science 20, 39-47.

Kim, D. S.(1929). The new bright for the cripple, Deaf and Mute could hear and speak. Journal of "Byeolgeongon"20, 80-81. April 1.

Kyunghyang Shinmun Newspaper(1948). October 17.

Kyunghyang Shinmun Newspaper(1969). June 4.

Kyunghyang Shinmun Newspaper(1970). July 17.

Kyunghyang Shinmun Newspaper(1971). April 30.

Kyunghyang Shinmun Newspaper(1973). November 5.
Lee, J. W.(2006). Adhocracy Procedure and Changing Process of National Sports Games for the Disabled in Accordance with Policy Dilemma in Disability Sport. Korean Journal of Adapted Physical Activity. 14(3), 65-86.

Lee, J. N.(1990). A Study historical process of curriculum development for the visually handicapped. Master Degree. Department of Special Education The graduate school of Education at Dankuk University.

Lee, H. J.(2010). Development of a prototype in the National sports games for the people with a disability according to the change in Korean society. Doctoral Degree. The graduate school of Physical Education at Soonchunhyang University.

Maeil Sinbo Newspaper(1911). June 1.

Ministry of Culture, Sports and Tourism(2018). PE White Paper. Seoul: Korea Sport Science Institute Report.

Ministry of Culture \& Tourism(2007). Paralympic White Paper. Seoul: Korea Sport Science Institute Report. 9-11.

Ministry of Education(1967). 文敎部 Curriculum Decree 181. April 15.

Ministry of Education(1974). 文敎部 Curriculum Decree 334. January 31 .

Ministry of Education(1983). 文敎部 Curriculum Notice 442. December 31.

Ministry of Education(1987). 文敎部 Curriculum Notice 87-7. March 31.

Ministry of Education(1987). 文敎部 Curriculum Notice 97-9. June 30

Ministry of Education(1988). 文敎部 Curriculum Notice 88-7. March 31.

Ministry of Education(1998). 敎育部 Curriculum Notice 1998-11. June 30.

Park, S. J.(1929). The new bright for the cripple, a new novelty! How to open the eyes of the blind. Journal of "Byeolgeongon"20, 77-79. April 1.

Roh, H. K., Hwang, S. H.(2014). A Study on Transition Process about Law related with Disability Sport of Korea, Japan and America. Korean Journal of Adapted Physical Activity.

Seoul Economic Newspaper(2010). April 8. 


\title{
한국 특수학교 체육과 장애인 체육환경 시대별 변화과정 탐색
}

\author{
남덕현 \\ 한국교원대학교 강사
}

[목적〕 본 연구는 특수학교의 체육교과 변천과정을 살펴본 후, 시대별 장애인 체육환경이 어떻게 변화해왔 는지에 대한 과정을 심층적으로 파악하는 것이다. 〔방법) 연구방법은 논문, 기관 보고서, 신문을 분석하는 문 헌연구를 하였다. 구체적 과정은 장애인체육 자료 검증을 위해 장애인체육 전문가 및 역사학자를 통해 연구주 제와 수집 자료의 연관성 여부를 확인하였다. 〔결론) 첫째, 특수학교의 체육 운영의 과정은 다음과 같다. 1940 50년대 특수학교는 체육은 단순히 체조 중심으로 시행되었으나, 1960년대 이르러 장애인 특성별로 학교가 분화되고 체육도 제도적 기반을 조성했으나 일반인 체육 운영을 모방한 수준이었다. 1970 80년대 특수학교는 교과 수 증가 및 장애 극복 프로그램 강화에 따라 체육 시간이 축소되었다. 1990년대 들어서 특수 체육 교과가 신설됨에 따라 맞춤식 장애학생 운동처방이 시행된다. 둘째, 장애인체육 운영 변화과정은 다음과 같다. 1960 70년대 장애인체육은 특수학교 중심의 체육활동이 주류였던 것에 반하여 1980년대 장애인체육 은 정부 주도로 범위가 확대된다. 특히, 88 서울올림픽과 서울패럴림픽 개최는 장애인체육의 제도, 조직, 시설 을 갖추는 계기를 마련한다. 1990년대 장애인체육은 학문적 발전 성과를 보였다는 점에서 의미를 보였으며 2000년대의 장애인체육은 1980년대의 양적 성장과 1990년대의 학문적 토대를 바탕으로 법적 토대 구축은 물론 장애인의 복지 여건의 개선을 이루게 된다. 위의 내용을 참고하여 미래에는 장애인을 위한 체육의 가치를 보다 합리적으로 해결할 방안을 모색해야 할 것이다.

주요어: 특수학교, 체육, 교과과정, 장애인체육, 서울올림픽, 서울패럴림픽 